\title{
Finding a Relatively Flat Archaeological Site with Minimal Ceramics: A Case Study from Iraqi Kurdistan
}

\author{
Mark Altaweel
}

Andrea Squitieri

\begin{abstract}
We present a new technique to detect flat archaeological sites with minimal ceramics using an unmanned aerial vehicle that maps surface stone concentrations. Methods deployed include point pattern analysis of stone concentrations and a machine learning technique using unsupervised classification of visible stone signature qualities, where these results are used in linear regressions to compare with geophysical and ceramic surface survey results of a site in Iraqi Kurdistan. There is a stronger fit $\left(r^{2}=0.77\right)$ between surface stone concentrations and architecture identified by geophysical measurement, while surveyed ceramics show a weaker fit to defined architecture $\left(r^{2}=0.31\right)$. Surface stone concentrations are potentially a better proxy than ceramics for determining the presence of past settlement in regions where stone was commonly used, sites are relatively flat, and ceramics are found in low concentrations. The methods advanced here can be scaled to wider areas, particularly in mountainous regions, with surface stone features present.
\end{abstract}

Keywords: remote sensing; site detection; geophysics; stone concentration; pottery survey; image classification; UAV; machine learning

\section{Introduction}

Archaeological sites in the Middle East have long been identified with ancient accumulated mounds of cultural debris, often consisting of adobe architectural elements such as mud brick (Adams 1981; Kouchoukos 2001; Wilkinson 2003). More recently, satellite remote sensing and unmanned aerial vehicles (UAVs), along with different field survey methods, have been used to identify and date archaeological sites (e.g., see Casana 2014; Ur et al. 2013; Wilkinson et al. 2012). Most of these methods depend on visible surface or near-surface architecture, mounding, and/or the presence of ceramic pottery sherds to identify whether a given site was the location of an earlier human settlement. While these methods are valid and have led to the discovery of thousands of sites, archaeologists in the region still lack methods for quickly identifying ancient sites in locations where a site might be relatively flat or cultural remains, such as ceramics, on the surface of a site are few. There is a demand for methods that utilize aerial imagery to make rapid identification of past settlements possible, and such a method should be extensive enough to allow broad surveys of wide geographical areas.

In north-eastern Iraq, archaeological sites are often located in intermontane valleys formed from sedimentary rocks, like limestone or conglomerate, suitable for the construction of buildings (Jassim and Goff 2006; Sissaskian and Fouad 2015). As a result of the use of these materials, concentrations of surface rocks are evident in archaeological sites in this region. This fact can potentially be used, along with the presence of ceramics and other measurements, to indicate the presence of archaeological sites. The detection of relatively higher concentrations of surface stones could indicate human activity, particularly the activity associated with settlement occupation.

In this paper, we present a site detection approach that detects rock debris or surface stone concentrations and then analyzes that data to identify whether these concentrations deviate from the wider background of stone concentrations. Our intent is not to invalidate other remote sensing or survey techniques that identify archaeological sites, particular those used for identifying mounding or the presence of surface ceramics, but our method is specific for identifying potential archaeological sites that have a relative flat quality and often lack surface ceramics. Additionally, 
the method is specific to sites that have concentrations of surface stones. The use of UAV imagery allows stone concentrations to be classified on the basis of their visible qualities which can then be mapped and analyzed using point pattern analysis. The utilization of linear regression to compare surface rock remains, geophysical features, and surface ceramics allows us to indicate the benefits of the approach and validate the results against other measures. Our overall approach demonstrates that identifying deviations in background stone concentrations could prove to be useful for archaeologists in similar regions, where minimal ceramic sherds are evident, mounding is either low or not easily visible, and surface rock remains potentially indicate the presence of past architectural features. The method is extendible and could potentially be deployed across wider areas to discover new sites. Similar to other remote sensing methods, the identification of sites in the approach advanced requires ground truthing, but the identification of potential sites can aid in a more rapid understanding of a given landscape where the presence of flat sites with minimal ceramics are evident.

The paper begins by providing a background to approaches that also utilize a combination of imagery and ground surveys in the Near East. The case study presented here derives from the Peshdar Plain in Iraqi Kurdistan. The methods used are then presented, along with our validation technique for demonstrating its utility for the detection of past settlement. We follow with the results we achieved for the methods applied. A discussion on the utility of this approach is then presented. Finally, wider conclusions, limitations, and possible extensions of this work are proposed.

\section{Background}

One reason why the Near East, and similarly Central Asia, North Africa, and southeastern Europe, have gained much interest by scholars focused on settlement archaeology is because archaeological mounds, or tells (Arabic; grdi in Kurdish; tepe in Farsi; höyük in Turkish), through their built-up debris, are often a clear indication of ancient settlement (Banning 1996; Hiebert 1991; Kemp 1977; Lloyd 1963; Rosen 1986). While an archaeological mound does not always demonstrate the full extent of a settlement's occupation, it is often the site of a major part or even the central area of an ancient settlement. This is particularly true of Bronze Age sites (c. 3000-1200 B.C.), when mounds were often the locations of key temples, political institutions, and other elite buildings (Wilkinson 2003). Few other regions in the world today have such a wealth of settlement remains dating to antiquity that are so clearly identifiable and widespread.

\section{Remote sensing data}

In more recent decades, satellite imagery has greatly enhanced the discovery of archaeological sites throughout much of the Middle East, including the Levant (Israel, Lebanon), parts of Anatolia (Turkey), Iran, Mesopotamia (Iraq and Syria), Egypt, and other regions of major settlement (e.g., Altaweel 2005; Kouchoukos 2001; Menze and Ur 2012; Parcak 2007; Philip et al. 2002). Different forms of satellite imagery have been utilized for the detection of sites, including popular datasets such as the CORONA satellite images, generated from the 1950s to the 1970s (Kennedy 2002) and high resolution images from the QuickBird (Lasaponara and Masini 2007), IKONOS (Beck et al. 2007), and WorldView (Parcak and Tuttle 2016) satellites. Additionally, multispectral reflectance satellites, such as the Advanced Spaceborne Thermal Emission and Reflection Radiometer (ASTER), have demonstrated utility in finding a variety of surface and near surface features, including ancient roads, canals, and settlements (Altaweel 2005). This includes using such multispectral imagery for detecting the presence of anthropogenic soils as markers of past human settlement (Menze and Ur 2012). Imagery also enhances our understanding of past socialenvironmental interactions, including taphonomic processes that shape settlements. Remote sensing, in combination with GIS, has been typically used for the detection of archaeological sites, where ground truthing has helped to validate observations (Hritz 2014). 
More recently, UAV imagery has facilitated the identification of mounded and other sites (Casana 2014). Surface pottery collection has also been extensively used by archaeologists to identify sites, by validating what is observed in imagery, and by establishing site chronological horizons (e.g., Beck and Philip 2006; Kennedy and Bewley 2009; Ur et al. 2013; Wilkinson). However, these methods may prove to be less effective in regions where past settlements were relatively flat and where the surface either lacks ceramic remains, or the density of the surface ceramics is generally low by Middle Eastern standards. In such cases, using the background geology and imagery of stone concentrations could help detect archaeological sites. This is particularly the case in areas where stones have been used in construction activity since the early phases of the Neolithic spanning over 10,000 years from the present (e.g., Finlayson et al. 2011).

\section{Surface survey collection}

Surface survey has been a long-standing technique in the Middle East for detecting past settlements; this method utilizes the often high concentrations of ceramic sherds on site surfaces to distinguish the presence of past human activity and occupation (e.g., Adams 1981; Braidwood 1937). One reason why this has worked so well in the Middle East is because ceramics, in combination with highly visible mounded sites and occasional surface ruins, provide a clear indication of ancient settlement. Southern Mesopotamia, amongst other regions, where researchers have taken advantage of ceramic concentrations on highly visible large mounds (e.g., Adams 1981; Gibson 1972; Finkbeiner 1991), is an excellent demonstration of the utility of this method. With only a modest amount of work relative to the information gathered, one could survey a settlement and obtain a reasonable estimate of its size and occupation periods (e.g., Wilkinson and Tucker 1995). In the Middle East, taphonomic processes sometimes flatten or makes mounded regions less visible or there is a significant alteration of the site's appearance over time. Surface ceramics can be battered and repeated plowing could make detection of ceramics difficult (Wilkinson 2000).

One potential problem in deploying surface reconnaissance is that it can be considerably less efficient in areas characterized by very low concentrations of surface ceramics, such as the plains within, and close to, the mountain region of Iraqi Kurdistan. Survey work there includes mounded settlements that have often proven to have relatively scant ceramic concentrations (Altaweel et al. 2012). Furthermore, not all sites demonstrate clear mounding. Sites mapped using UAV images or other tools may show low slopes (e.g., $<5 \%$ ) or low gradients (e.g., $<0.1 \mathrm{~m}$ ), making them difficult to detect and differentiate from the general topography. We refer to the sites that appear to most human observers to be relatively level with the plain as "flat sites," although the exact meaning of "flat site," or what measurement defines a site as "flat," is not easy to determine (Hofmann 2012). For this reason, alternative evidence for the presence of past human occupation that does not depend on mounding or ceramic concentrations might be needed. In mountainous regions with ample rock resources for construction, stones and their displacement during the course of human occupation could be an important indicator for the location of a past human settlement. In particular, anthropogenic activity (including the transportation of, and construction from, stone) may leave a clear indication of human use or occupation long after abandonment, while buildings themselves can be the source of stone concentrations that differ from their surroundings, signalling potential archaeological features within a landscape (e.g., Philip et al. 2002).

\section{The Dinka Settlement Complex}

In this paper, we show the results of testing such a complementary approach to site identification on the Dinka Settlement Complex, a site located in the Bora Plain, a subunit of the much larger Peshdar Plain in the Sulaymaniyah province of Iraqi Kurdistan (Figures 1a and 1b).

The Dinka Settlement Complex encompasses a heavily eroded natural hill, called Qalat-i Dinka, rising c. 40 metres above the surface, and flanked by the Lower Zab river to the south (Figure 2). To the north and the east of this hill, a large, relatively flat area extends, whose slope 
never exceeds 10 degrees. This contrasts directly with the slopes of Qalat-i Dinka, which can reach 89 degrees. Today, this area is mostly agricultural, consisting of plowed fields interspersed with smaller zones of low vegetation consisting of scrub and grass. This area also features a seasonal stream bed (or wadi) running north-south, parallel to a modern road. About 600 m east of Qalat-i Dinka, another modern intervention is visible: a chicken farm whose construction destroyed a shallow half-hectare mound called Gird-i Bazar (Figure 2). Initially, this small mound was believed to be the main archaeological site in the area, whereas the surrounding plain was thought to be devoid of ancient settlement.

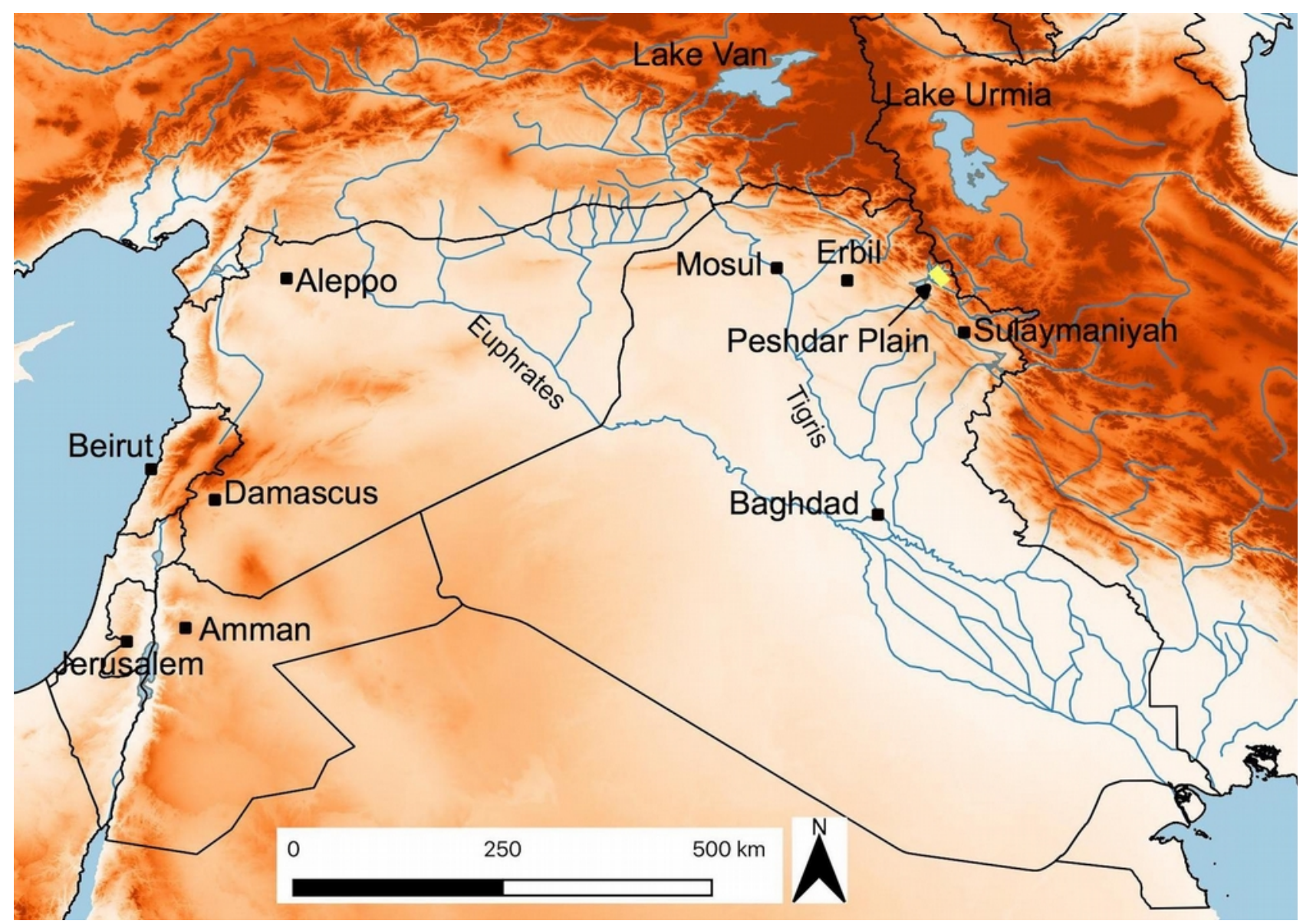

Figure 1a. Map of the Middle East showing the location of the Peshdar Plain where the site of the Dinka Settlement Complex lies.

Figure 1b. Map of the Peshdar Plain showing the location of the Dinka Settlement Complex. 

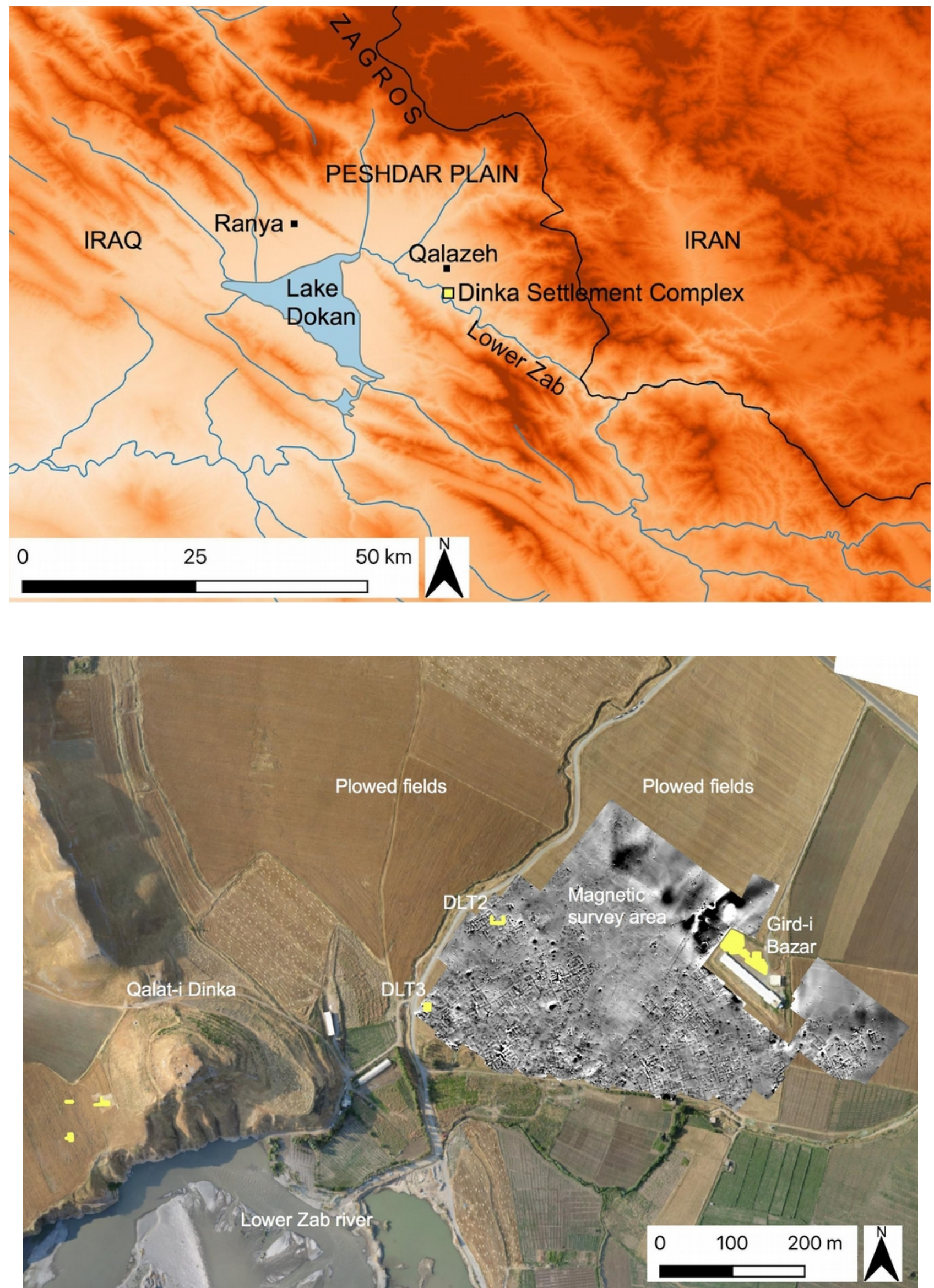

Figure 2. The Dinka Settlement Complex in the Bora Plain. In yellow the areas excavated so far by the Peshdar Plain Project (Orthophoto generated by ICONEM, courtesy of Jessica Giraud). In between Gird-i Bazar and Qalat-i Dinka the area covered by the magnetic survey is also shown. Magnetogram by Jörg Fassbinder and his team. 
The surrounding Bora Plain is the hinterland of the Dinka Settlement Complex. It is an alluvial plain whose main geological outcrops include Cretaceous period limestones, conglomerates, and sandstones, along with Quaternary period alluvial deposits (terraces) created by the Lower Zab river (Altaweel and Marsh 2016). These terraces and surrounding region are made of pebbles, cobbles, and boulders of limestone and silicate, alternating with lower concentrations of metamorphic and igneous rock (Sissakian et al. 2016, 50). The ready availability of sedimentary and, to a lesser extent, metamorphic and igneous rock created an immediate resource for building materials.

In 2013 and 2015, a surface reconnaissance recovering pottery sherds over an area of about 60 ha in total was conducted, encompassing Qalat-i Dinka, Gird-i Bazar, and the flat area in between them (Giraud 2016). Based on the pottery spread, this survey indicated that there had possibly been a settlement near Qalat-i Dinka, along the relatively flat plain (Giraud 2016). Ceramics are often present on plains as they were utilized, along with organic materials, for fertilizing crops. Thus their presence does not always indicate a past settlement (Wilkinson 1982). In such cases, low ceramic concentrations can be found, but these are generally fewer in number than places where past settlement is evident. Over an area of 60 ha, only 776 diagnostic sherds were recovered (Giraud 2016), which was seen as low by Middle Eastern standards. The results of this did not confirm there was a site present, although ancient anthropogenic activity was clear.

Because we did not know that a site was present in the area, excavations of geoarchaeological trenches in the autumn of 2015 commenced in order to sample wider environmental background data for the region. Accidentally, these trenches confirmed that there was, indeed, an archaeological settlement based on the presence of in situ architectural elements found below the surface. These trenches, opened between Qalat-i Dinka and Girdi-i Bazar in the plowed area, showed that the settlement extended over this flat region. A charcoal sample for ${ }^{14} \mathrm{C}$ collected from one trench was dated to 830-789 cal B.C. (Altaweel and Marsh 2016, 28), matching the surface pottery evidence that dated to the Iron Age horizon (c. 1200-550 B.C.). Furthermore, evidence from these trenches made it clear that most of the rocks visible on the surface between Qalat-i Dinka and Gird-i Bazar had not accumulated there as a result of natural phenomena but through anthropogenic transportation. In the sections, large stones, mainly in the form of cobblestones and some boulders, were only related to architectural elements, mainly the walls of buildings, and no natural circumstances were observed that could offer an alternative reason for the location of these stones.

Final validation of the existence of an extended settlement came from a surface magnetic survey conducted over the same area and surrounding plain (Fassbinder, Ašandulesei and Scheiblecker 2018, 2017). This survey revealed that underneath the plowed area in between Qalat-i Dinka and Gird-i Bazar were many architectural features that could be interpreted as houses, public buildings, and workshops, based on their layout (Figure 2). The magnetic survey also identified zones devoid of architecture ("gap areas"), which are further discussed below. Thus, we had initially started out in 2015 believing the site was much smaller, but this view changed based on the geoarchaeological work and later geophysical prospection. This also prompted a rethink in how such a flat site, with minimal ceramics, could be better detected using only its surface qualities.

Additionally, the archaeological excavations conducted in several operations within the settlement (Figure 2, see highlighted areas) proved the existence of stone architecture by unearthing a series of buildings whose foundations, lying on virgin soil, were composed of medium-sized cobblestones, most of them in limestone, similar to those found on the surface of the plowed area. This was seen not only in Gird-i Bazar (Radner, Kreppner and Squitieri 2016) but also in the lower town (operation DLT2; Radner, Kreppner and Squitieri 2017, 31-52; operation DLT3: Squitieri 2018). The excavations also confirmed the settlement's Iron Age dating through the radiocarbon analysis of short-lived samples (Radner, Kreppner and Squitieri 2018, 31, 56-8), and this analysis provided no evidence for occupation later than the Iron Age in the area between Qalat-i Dinka and Gird-i Bazar. The latter was reused as a cemetery area during the Sasanian period (c. AD 224-651); however, no contemporaneous architectural features have been found (Downey 2018). 
The geoarchaeological trenches, the excavations, and the magnetic survey all strongly suggested that the concentration of cobblestones on the surface most likely related to the architecture underneath the surface revealed by the geophysics. Therefore, these rocks potentially signalled the site's existence when measured against the background presence of stones in areas that showed no clear indication of human occupation. The results also indicated that sherd scatters, while suggestive of possible archaeological remains below the surface, are not always clear indicators of the existence of archaeological sites, given the lack of mounding in the area and the relatively low number of diagnostic sherds across a relatively large area.

\section{Methods}

Our intent is to present a new method that uses UAV imagery to detect the presence of a site that is relatively flat and has few surface ceramics in a region where such sites might be common. The method detects anomalies of surface stone pattern concentrations that are different from surrounding areas. Thus, differences in stone patterns are what enables the detection of a possible site. However, similar to all remote sensing methods, validation, or rather ground truthing, that a site is observed is needed. Such a validation can come in the form of many different techniques, including use of a magnetometer, some form of surface reconnaissance, or excavation. For our demonstration that the technique has validity in finding undocumented archaeological sites, and in order to test the assumption that a relationship existed between the surface stone concentrations and the as-yet unexcavated architecture, several methodological steps were applied. The first utilized remote sensing of imagery from a UAV. This collects the needed data to show surface stone anomalies potentially differ from the normal background. The step also includes a machine learning technique to distinguish stone features from other materials. The next step is validation of these results, which establishes that a site does exist and identifying site locality relative to the surface stone concentrations. The surface ceramic survey data are also used as an additional step here to compare these with the surface stone concentration. The final stage involved point pattern analysis, which demonstrates where stones concentrate on the surface, while a regression analysis compares this result to the other results collected via geophysics and surface survey. Overall, the method advanced here is 1) the identification of surface stones and 2) distinguishing surface stone concentration using point pattern analysis. The other methods are used for validation or comparative purposes. While this method identifies potential archaeological sites, the final result should be ground truthing that validates the observation.

\section{Remote sensing and classification approach}

The Bora Plain was mapped over an area of about 50 ha using a DJI Phantom 4 Pro UAV, flying at an altitude of about $80 \mathrm{~m}$ above the ground. The UAV's camera has a 1-inch 20 megapixel CMOS sensor with a mechanical shutter that eliminates the distortions that can occur when photographing at high-speed. Ideally, either a thermal or multispectral imaging camera would have been used, but neither of these were available to us. As the camera on the UAV was limited to visible light, conditions that optimized results were utilized. In particular, the scanning flights were conducted during a period when the sun was well above the horizon, creating a relatively even distribution of light across the surface of the plain. After these flights were completed, the UAV photos were processed in Agisoft Photoscan to create several orthophotos of the area scanned.

The orthophotos were then processed using Environment for Visualizing Images software (ENVI 5.4) to generate a pixel classification and automate the identification and tallying of surface stones by image colour, using an unsupervised classification. Some roads and a wadi were excluded from analysis, as these were sites of artificial concentrations of rocks (the result of water transport and clearly modern human intervention). Gird-i Bazar, with its recently-built chicken farm, also constituted an element of recent disturbance (Figure 3). Our approach entailed using a machine learning technique that deploys a k-means cluster analysis with 24 classes; after experimenting with 
a variety of implementations and number of classes, only two iterations were needed using the classes applied to the merged images (Richards 2013a). The number of classes allocated provided sufficient visual differentiation between the different natural and anthropogenic features on the imagery. Once the classes were produced, they were checked to see which classes best identified rocks on the surface of the image. The resulting classifications were exported as a shapefile into QGIS (v. 3.4) to be compared with the original orthophotos in order to single out which pixel classification(s) better matched the surface stones, as well as to identify areas with a strong background noise. The shapefile thus obtained contained the stone counts (in polygons, which were then transformed into points) to be used for the analysis.

Only 1 of the 24 classes was determined to consistently define surface rocks: class 23 (Figure 3). The class output was further compared to the visual evidence of rocks on the surface throughout different parts of the imagery to confirm that the identified class did indeed indicate surface stones. There were some areas with vegetation where stones were not as easily visible either through on-site inspection or through the classification approach. Filtering the data did not enhance results. Based on this, these areas were also removed and not included in the overall analysis.

Figure 3 here

Figure 3. One of the orthophotos (orthophoto 1) created using the DJI Phantom 4 Pro drone overlaid by the stone concentration generated after processing the image in ENVI and selecting the blue class 23 . Note the areas with high disturbances (roads, wadi, chicken farm, areas with vegetation) that were excluded from the analysis.

In order to more systematically validate the k-means clustering method in terms of its precision in identifying surface stones, we used a 40 x $40 \mathrm{~m}$ grid spread over both settlement and non-settlement areas with 119 squares equivalent to an area of 14 ha. We sampled 9 random squares in the grid by comparing the number of marked stones from the unsupervised classification with the total number of stones visible in the orthophoto (Figure 4). Overall, the k-means clustering method proved to have $93.72 \%$ precision in identifying stone samples on the surface when comparing marked stones in the approach and those that could be visually identified in raw images. Moreover, a total of 345 false positives were found in the 9 sampled squares - cases when a non-stone feature was identified as a stone by the analysis. The positive predictive value (PPV) of the approach, which accounts for false positive identification of stones (that is true positives / (true positives + false positives)), was thus established as 0.96 (Table 1; Brenning 2009). This result was considered sufficient to identify stone feature concentrations.

$\begin{array}{lllll}\text { square ID } & \text { total stones } & \text { stone count (true positive) } & \text { positive match (\%) } & \text { false positive } \\ 29 & 439 & 376 & 85.64 & 55 \\ 30 & 1267 & 1233 & 97.31 & 32 \\ 61 & 2102 & 1967 & 93.57 & 56 \\ 75 & 1548 & 1527 & 98.64 & 39 \\ 80 & 501 & 474 & 94.61 & 21 \\ 102 & 1135 & 1025 & 90.3 & 23 \\ 107 & 860 & 749 & 87.09 & 44 \\ 141 & 940 & 934 & 99.36 & 32 \\ 162 & 367 & 356 & 97 & \text { Total=345 } \\ \text { Total } & \mathbf{9 1 6 9} & \mathbf{8 6 4 1} & \text { Avg.=93.72 \% } \\ \text { Table } 1 . \text { Calculation of the positive predictive value (PPV) accounting for false positive } \\ \text { identification of stones (that is true positives / (true positives + false positives)). The result was } \\ \text { established at }\end{array}$




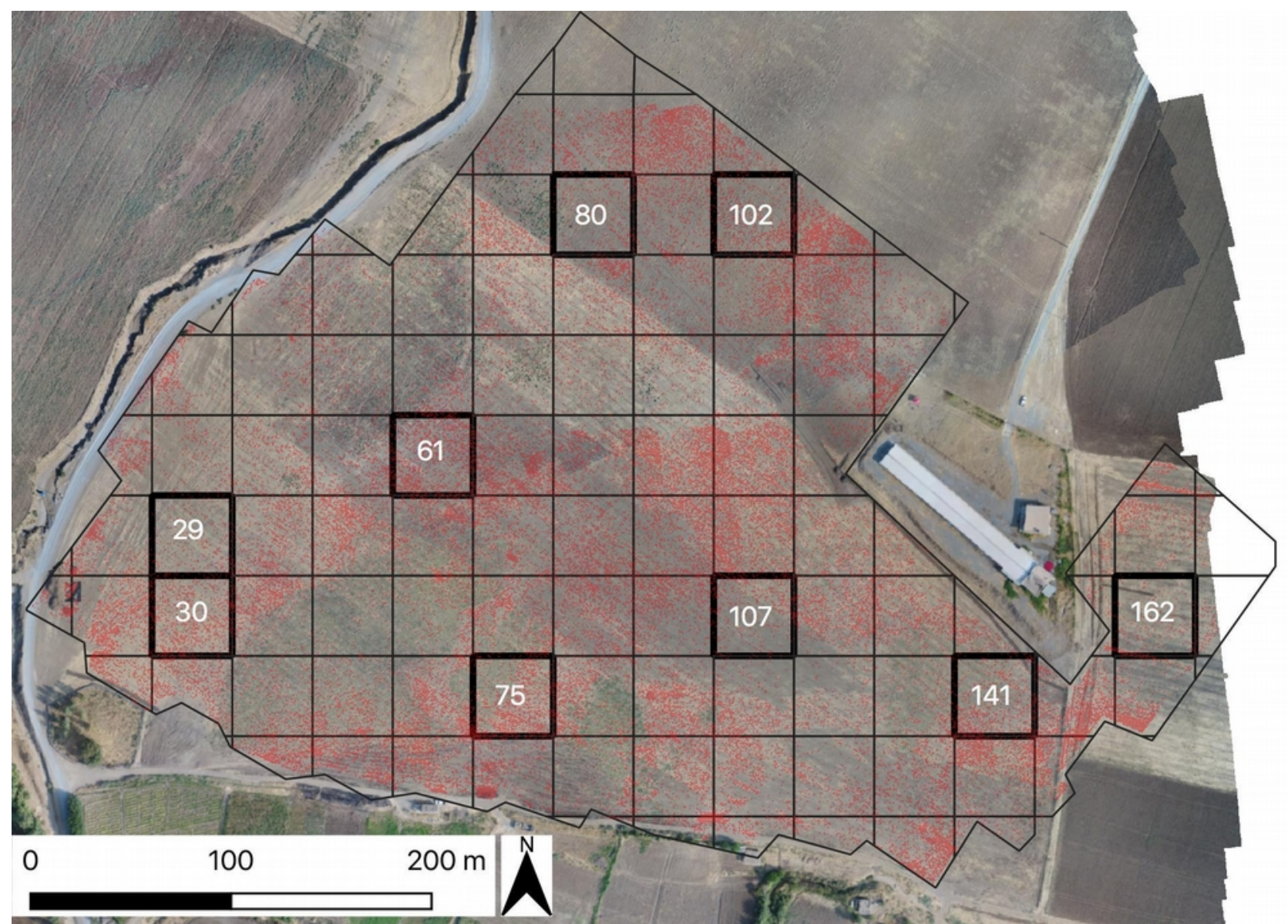

Figure 4. A 40 x $40 \mathrm{~m}$ grid spread over the settlement area with 119 squares equivalent to an area of 14 ha. 9 random squares were sampled in this grid to compare the number of marked stones from the unsupervised classification with the total number of stones visible in the orthophoto.

In order to automate stone detection, a machine learning supervised classification was also used, where training data was provided to determine relevant classes. The methods deployed included minimum distance and maximum likelihood classification using imagery that displayed different rocks and surrounding background imagery on the surface of the region of study (Richards 2013b). The results proved less effective, not because they did not work, but because they were too computationally expensive and time consuming to allow easy image processing. Because the unsupervised technique produced sufficiently accurate results in our case, it was deemed unnecessary to deploy supervised classification. Overall, although the limitation of this approach is the lack of spectral or other sensory data beyond the visible light captured through a normal camera, simply using such a camera proved relatively effective.

\section{Geophysical validation}

To further confirm the presence of an archaeological site, a magnetic geophysical survey was conducted using a caesium magnetometer Scintrex Smarmag SM4G-special in the so-called "dualsensor" configuration (Fassbinder, Ašandulesei and Scheiblecker 2017, 18; Figure 5). The use of a magnetometer here is needed as it demonstrates more definitively that there is an ancient site where abnormalities in stone concentrations are found. The total area surveyed extended across 13 ha (Fassbinder, Ašandulesei and Scheiblecker 2018). The area covered by the magnetic survey was considered to be "onsite" because it revealed areas where architectural features were clearly visible. Based on the layouts of the visible features, these have been interpreted as houses, mostly concentrated in the southern and south-eastern portions of the magnetogram, and public buildings (or more generically non-domestic buildings much larger than houses) located in the north-western 
area (Fassbinder, Ašandulesei and Scheiblecker 2018, 2017). The archaeological excavations largely confirmed the architectonic features visible in the magnetogram by unearthing stone walls following the magnetic anomalies (Fassbinder and Asandulesei 2016, Fig. B4.2; Radner, Kreppner and Squitieri 2018, 32; Figure 6).

Additionally, an area within the middle of the recovered architecture that contained no building remains was also considered "onsite" because this area was deemed to have been subject to erosion by natural forces, most likely a seasonal wadi that ran through the site after its abandonment. This reconstructed wadi was identified by a hydrological analysis conducted in GISSAGA and confirmed by three 2018 geoarchaeological trenches (see Radner, Kreppner and Squitieri 2017, 177-8; Squitieri 2018). Moreover, the architectural features on both edges of this gap area show signs of destruction, which fits with the interpretation of an ancient wadi that may have destroyed such features (Fassbinder, Ašandulesei and Scheiblecker 2017, 27).

In the northern part of the magnetogram another gap area, containing no evidence of architecture, is present. Unlike the gap area discussed previously, here there are no signs of erosion. Therefore, the settlement is considered to end in this area, and the "offsite" area is considered to be outside the magnetic surveyed area, to the north. While the geophysical survey was performed at an earlier time, it allowed us to identify the built-up areas by helping quantify the architectural features $\left(\mathrm{m}^{2}\right)$ visible in the magnetogram and distinguish areas where no architecture was evident. These results could then be compared to the presence of surface stones identified using imagery.

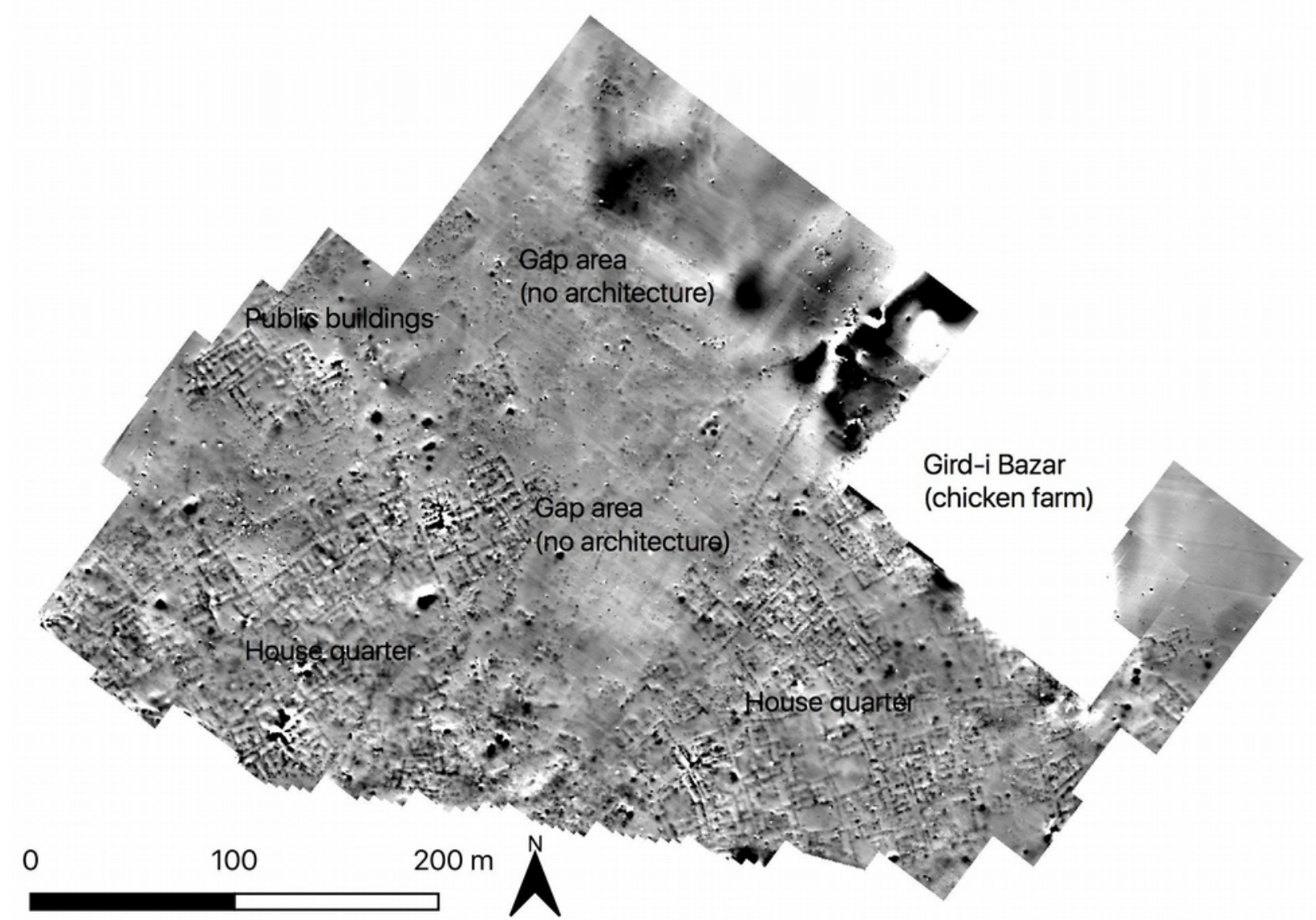

Figure 5. Magnetogram with the results of the 2016-2017 magnetic survey of the Dinka Settlement Complex. The survey was conducted using a Scintrex Smartmag SM4G-Special and Geometric G858 total field magnetometer in duo-sensor configuration by Jörg Fassbinder and his team (after Fassbinder, Ašandulesei and Scheiblecker 2017, Fig. B1.5).

Figure 6. Two detail images of the magnetogram overlain by the excavated stone walls. On the left: operation DLT2; on the right: Gird-i Bazar, western area. See Figure 2 for an overview of the excavated areas. 

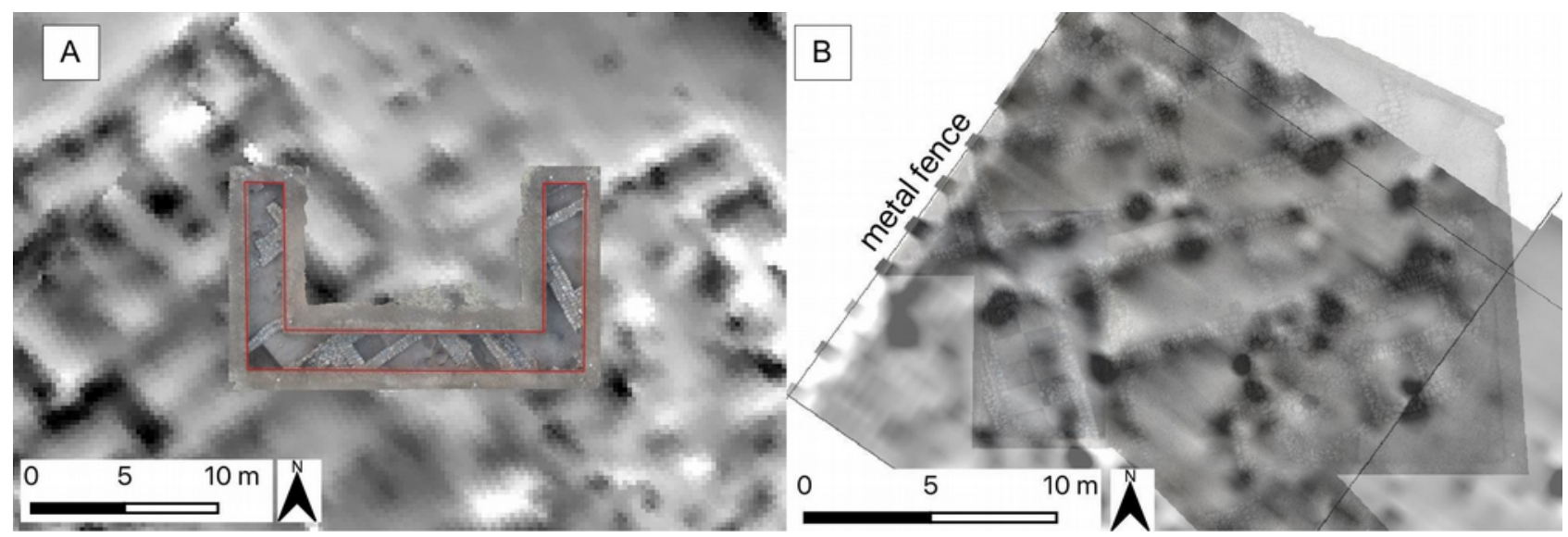

\section{Surface ceramic collection}

The original surface ceramic collection (Giraud 2016) was organized in collection zones across an area of approximately 60 ha, encompassing Gird-i Bazar, Qalat-i Dinka, and the area in between them. Eleven of these collection zones coincide with the area covered by the magnetic survey (Figure 7). For this work, because the area surveyed for the pottery sherds was much larger than the area covered by the magnetic survey, it was necessary to normalize the number of sherds collected from each zone to the actual area in $\mathrm{m}^{2}$ covered by the geophysical survey in each of the collection zones. The normalization of results allowed the built-up area from the magnetometry results and surface ceramic survey area to be compared to the concentration of surface stones.

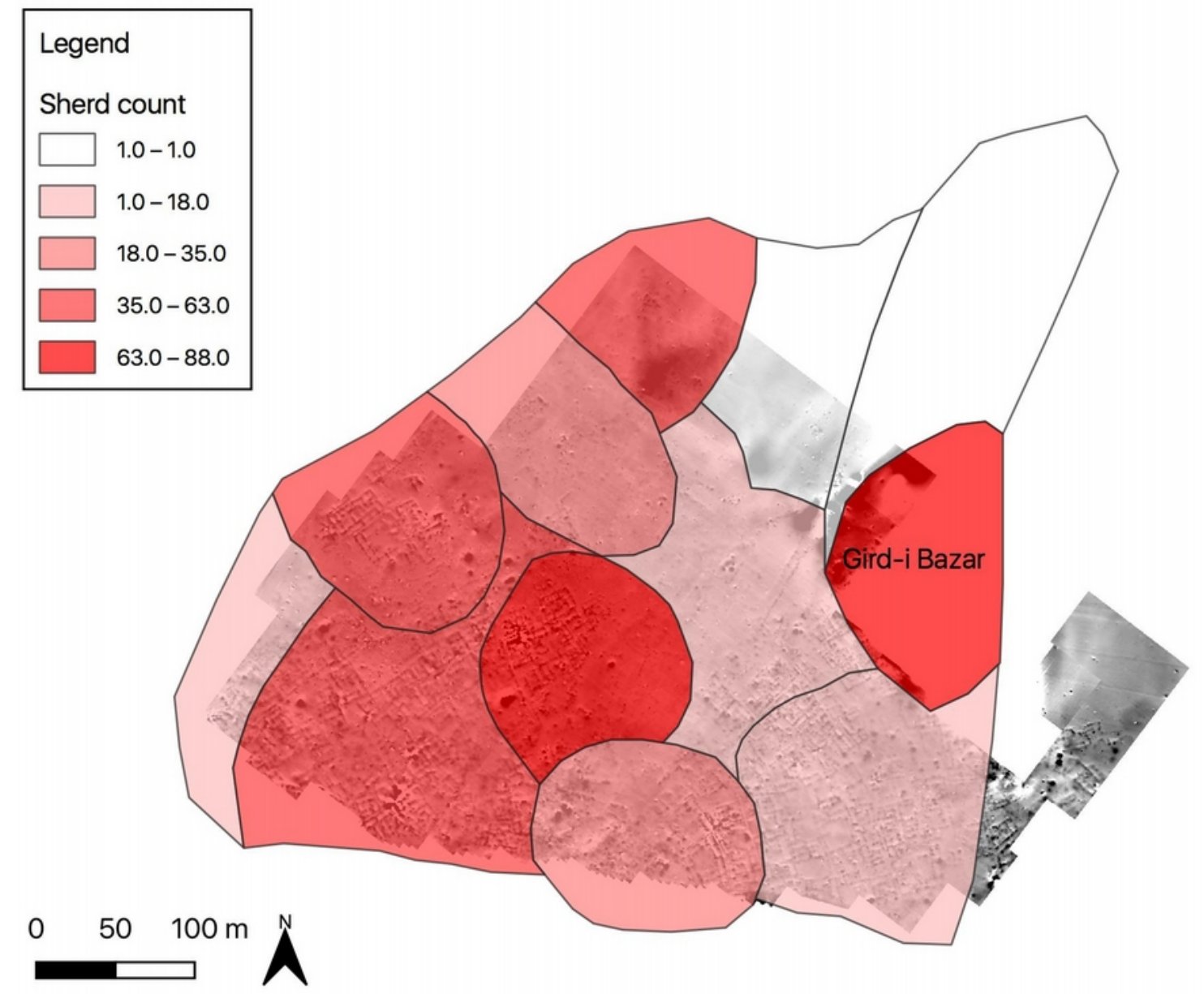

Figure 7. The pottery collection zones over the magnetic surveyed area and the relative sherd count (non-normalized, based on Giraud 2016, Figs. B3.3a-b). Pottery data, courtesy of Jessica Giraud. Magnetometer by Jörg Fassbinder and his team (Fassbinder, Ašandulesei and Scheiblecker 2018, 
Fig. B2).

\section{Point pattern analysis and regression}

Once stones were determined to be present via the unsupervised classification, then it was necessary to see where stones concentrated and how patterns of concentrations differed across the analyzed imagery. To accomplish this, a point pattern analysis was carried out. A k-nearest neighbor analysis was run in the R statistical package (v. 3.2.3) using the point-shapefile with the stone counts, in the area covered by both the geophysical and surface surveys, covering on- and off-site regions. "Onsite” is defined as the area containing evident architecture, found using geophysics and excavations, while "off-site" is defined as the area outside of this. Within the architectural area, there is one large region that had no evident architecture but was interpreted as having been eroded after settlement abandonment. The area is next to an ancient wadi, no longer visible, and subsequent excavation did reveal signs of eroded building remains, including tumbled bricks and stone architecture (Fassbinder, Ašandulesei and Scheiblecker 2017, 27, Fig. B1.11; Radner, Kreppner and Squitieri 2017, Fig. H2). In the k-nearest neighbor analysis, the expected result was a recognizable difference in surface stone clustering in between the two areas: those that were interpreted as on-site and those that were considered to be off-site.

A regression analysis was chosen to compare how well results from the different site proxies related to each other, that is, how well the geophysical, UAV images, and ceramic surveys related to each other. This helped to establish how well proxies such as stones and ceramics demonstrate the presence of an archaeological site as determined by geophysics. Three variables were compared through a linear regression analysis using the $\mathrm{R}$ statistical package. The first was the stone count obtained from the pixel classification result of the orthophotos; the second was the pottery sherd count from the surface pottery collection; the third was the built-up area covering the area in $\mathrm{m}^{2}$ for the defined structures visible in the magnetometry results.

\section{Results}

\section{Image classification results}

The comparison of the pixel k-means classification with the original orthophotos has shown that the classes numbering 3, 22, 23 and 24 (corresponding to four different shades of blue) were the most effective in identifying stones on the surface of the plowed area (Figure 3). Among these, we chose class 23 for the analysis because it had the best and most comprehensive results in the true positive to false positive ratio.

For the subsequent k-nearest neighbor analysis, we used two classified orthophotos. The first covered the same area as the magnetic prospection in which the architectural features were shown; the second orthophoto extended north and west of the first, into the area of plowed fields. Figure 8 shows the area covered by orthophoto 1 and the area covered by orthophoto 2, with the stones shown as dotted features. As stated above, the wadi, modern roads, and areas with thick shrub vegetation were removed from orthophoto 2. It is evident from this image that we investigated both on and offsite areas. Figure 9 shows a heatmap based on stone counts for both orthophotos. We applied the analysis to the stone count from each orthophoto to establish whether the stones were more concentrated within the geophysics area (orthophoto 1) rather than outside of it (orthophoto 2). 


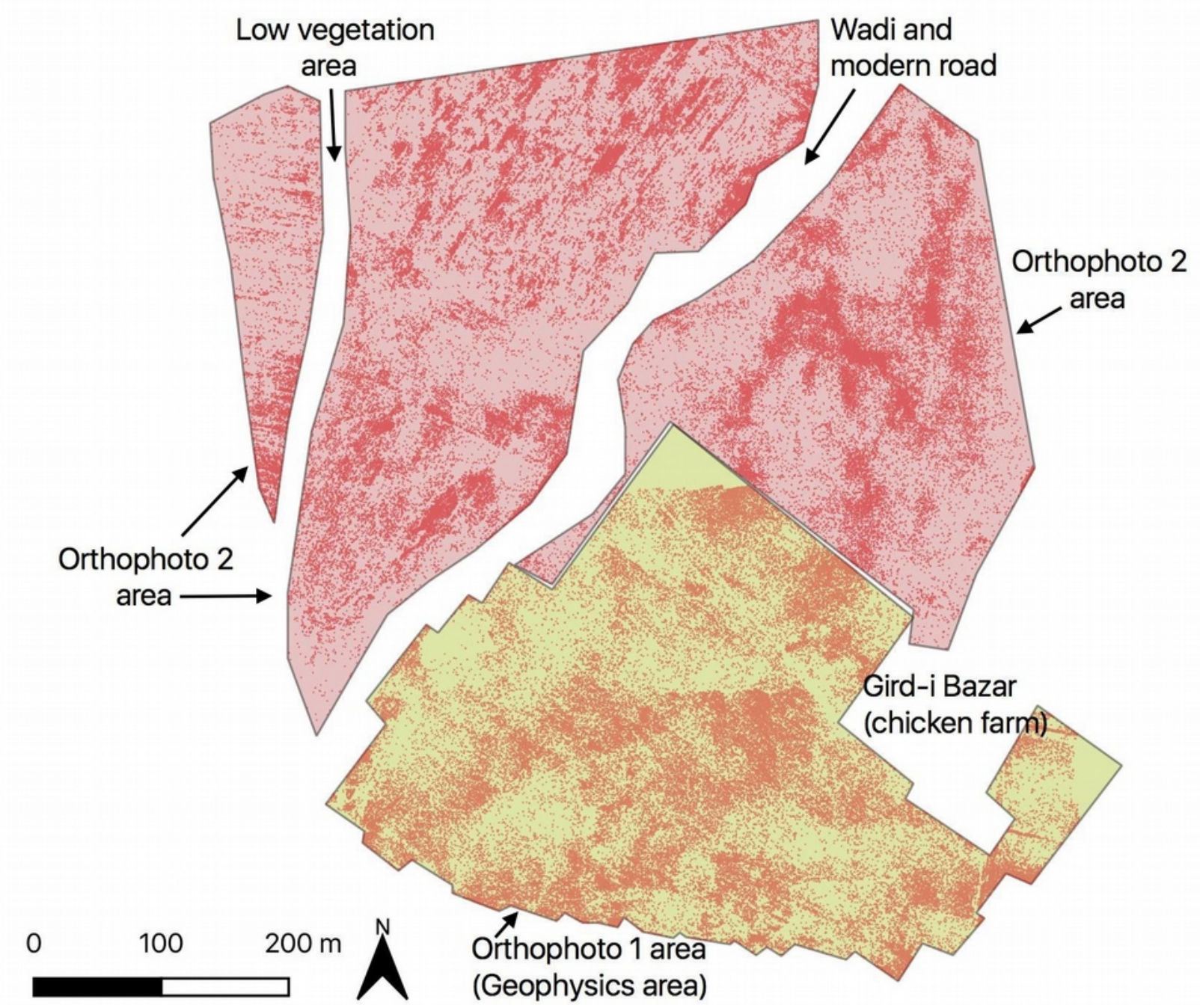

Figure 8. The onsite site area and the offsite area used for the analysis, with the stones represented by dots. The gaps indicate area removed from the analysis.

Figure 9. Heatmap generated in QGIS based on the shapefile with the stone count distribution over the onsite and offsite areas. 


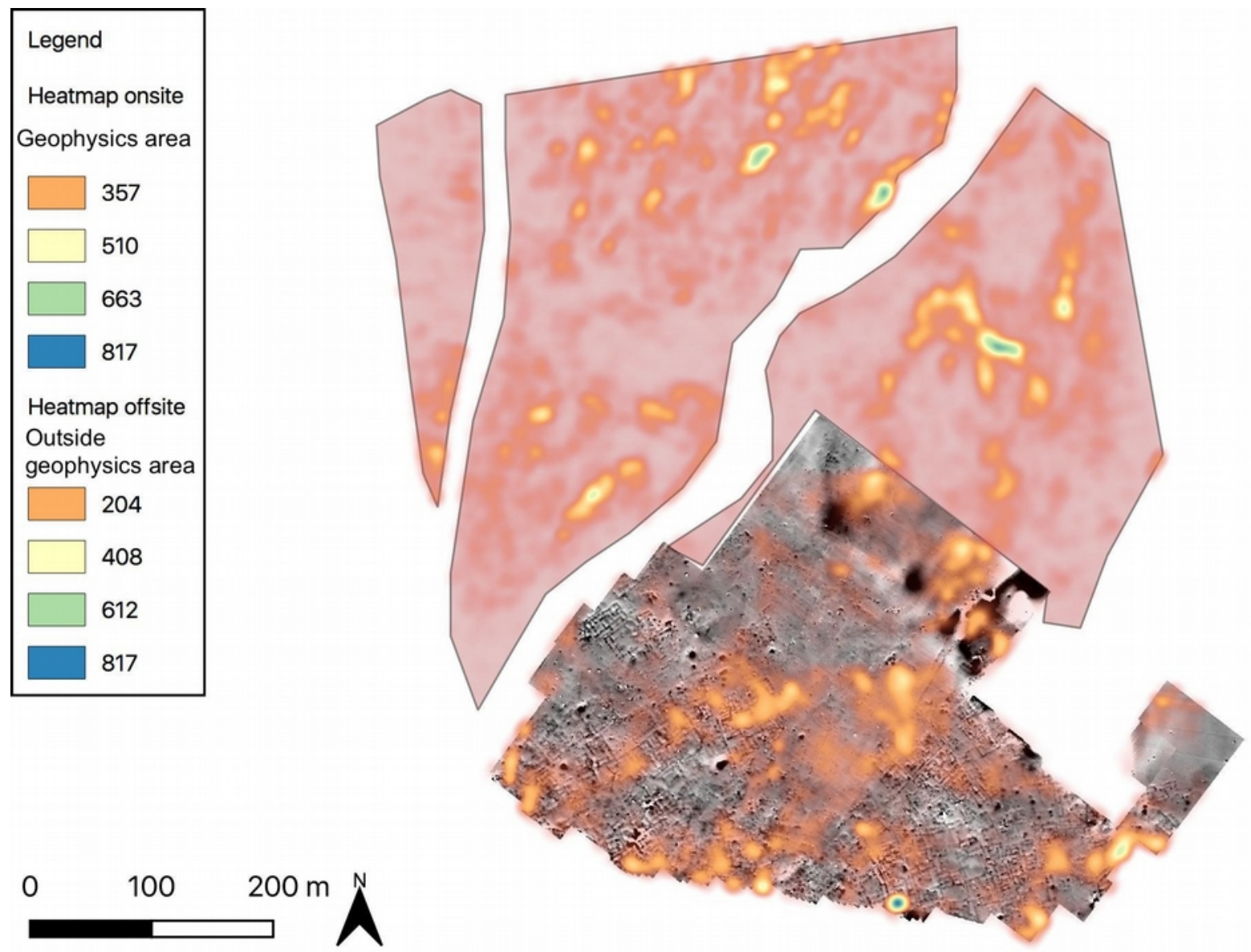

Surface stone comparison to ceramic survey and geophysics

The surface pottery collection was carried out in the collection zones given in Figure 7 . This figure shows that the raw numbers of sherds collected are not high, ranging between 1 and 88 diagnostic sherds. The zone with the most sherds is Gird-i Bazar, where the pottery collection took place before the chicken farm was built and this was the only assumed area that was originally thought to be an archaeological site. Pottery collection zones and geophysical areas did not match, so it was necessary to normalize the sherd quantities. Table 2 shows the numbers of sherds per collection zone normalized to the extension of the magnetic surveyed area in each collection zone (with the exclusion of the Gird-i Bazar collection zone), along with the built-up area and stone count for each zone. The linear regression analysis results among these three values are shown below.

$\begin{array}{lllll}\begin{array}{l}\text { Pottery collection zone Sherd count } \\ \text { ID }\end{array} & \begin{array}{l}\text { Normalized } \\ \text { sherd count }\end{array} & \text { Built-up area (m2) Stone count } \\ 1282 & 1 & 0.07 & 0 & 1635 \\ 1284 & 48 & 38.54 & 4070 & 3670 \\ 1285 & 42 & 25.48 & 0 & 3964 \\ 1286 & 35 & 26.87 & 1686 & 3603 \\ 1287 & 18 & 6 & 746 & 2043 \\ 1288 & 30 & 22.32 & 3626 & 9829 \\ 1290 & 10 & 8.69 & 9184 & 10593 \\ 1291 & 77 & 77 & 3896 & 12155 \\ 1292 & 1 & 0.45 & 0 & 5404 \\ 1298 & 63 & 52.98 & 8712 & 15477\end{array}$


Table 2. Table showing the numbers of sherds per collection zone normalized to the extension of the magnetic surveyed area in each collection zone, along with the built-up area and stone count for each zone.

Table 3 shows the results of the k-nearest neighbor analysis run on the stone count over the geophysics and outside of it (see Figures 8-9). It can be observed that the stones tend to cluster more inside the geophysics area than outside of it. The Nearest Neighbor Index (NNI) in the offsite area is 0.43 in comparison to 0.03 in the onsite area. This result can be connected to the presence of architectural features that have created a higher concentration of surface stones. It is possible that, as a result of erosion and plowing over time, the architectural stones were removed from walls and gradually brought to the surface (structures are less than one meter below the modern site surface), analogous to the mechanism responsible for the surface ceramic concentration.

Two regression analyses were run. The first regression analysis was run among the built-up area and the sherd count (normalized), based on values in Table 2. The result, shown in Figure 10, indicates a weak fit in the sherd counts and the built-up area, with $r^{2}=0.31$. Hence, although ceramic sherds tend to be more concentrated over the area above architectural features, the resulting weak fit can be accounted for by erosion phenomena and anthropogenic activities (e.g., intensive plowing) that may have dislocated the ceramics from the surface covering the architectural features.

The second regression analysis was run between the built-up area and the stone count. For the analysis, we first applied a fine-scale assessment of stones and built-up area through sampling squares of $150 \mathrm{~m}$ in a grid cropped at the edges to fit the geophysics area (Figure 11). This analysis gave a fit result of $r^{2}=0.66$ (Figure 12). Secondly, we divided the magnetogram area into five subareas, some with architecture and some without (Figure 13). The result, shown in Figure 14, indicates that a stronger relationship exists between these two variables, with $r^{2}=0.77$ - a stronger result than that obtained with the finer 150 x $150 \mathrm{~m}$ grid, or from the surface ceramic survey. Stones, in this case, are a better indicator of the presence of architecture below the surface than pottery, possibly because they are more visible or simply because there are greater concentrations of them relative to the wider areas around the site. However, stones, too, are likely to move, making this result potentially weaker. This is why the fit was weaker when a finer scale was applied than a larger scale. Nevertheless, these results show that stones still somewhat align to where architecture is found and at a value better than ceramics.

$\begin{array}{lrrr}\text { Location } & \text { Observed mean distance } & \text { Expected mean distance Nearest Neighbor Inex (NNI) } \\ \text { OFFSITE } & 0.3893 & 0.8962 & 0.4344 \\ \text { ONSITE } & 0.0155 & 0.5155 & 0.0302\end{array}$

Table 3. Results of the k-nearest neighbor analysis run on the stone count over the geophysics and outside of it. 


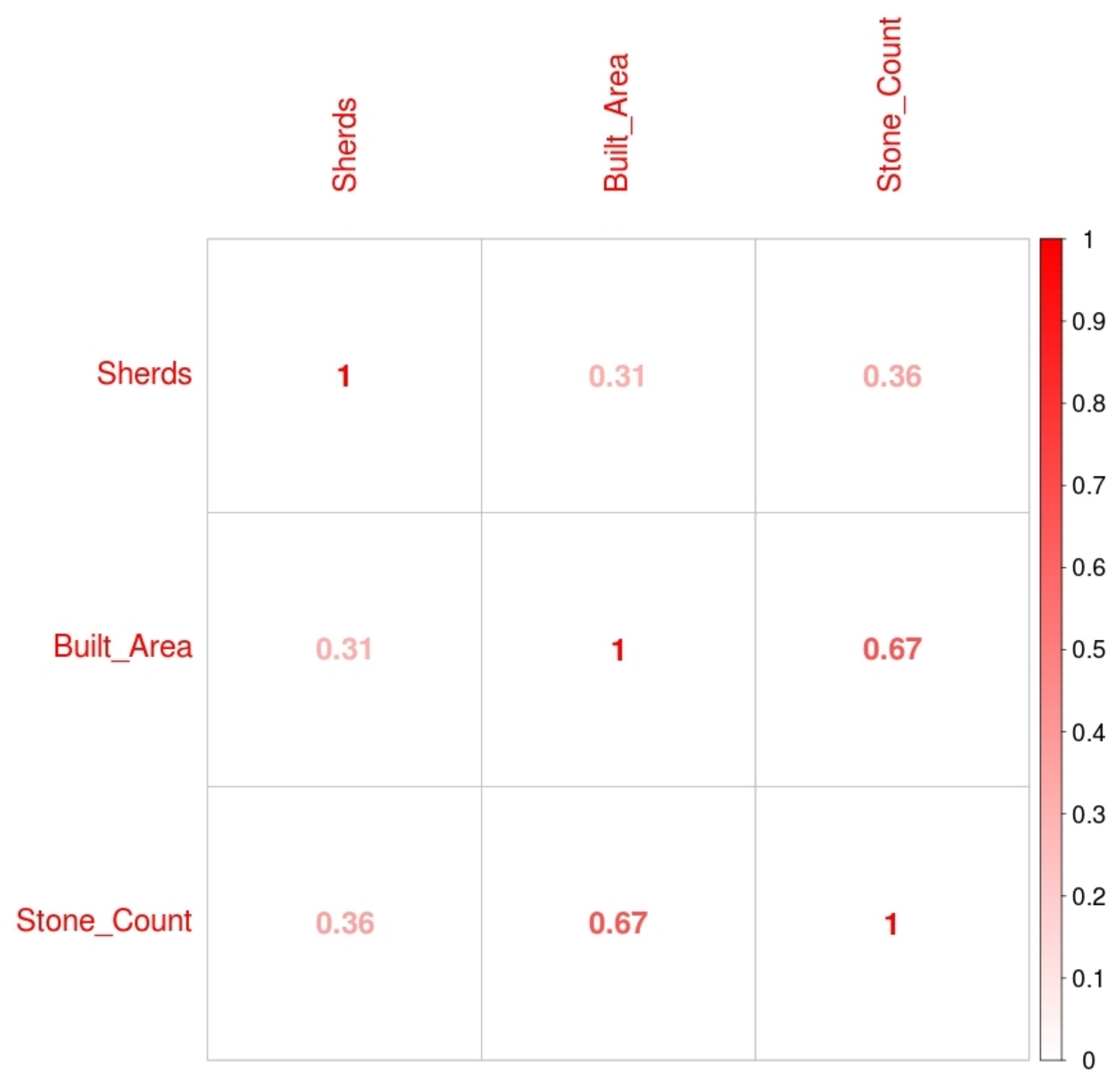

Figure 10. Results of the regression analysis between the pottery count (normalized) and the stone built-up area defined on the basis of the magnetic survey.

Figure 11. The $150 \times 150 \mathrm{~m}$ grid (cropped at the edges to fit the magnetogram) in which the magnetic survey area was divided to compare the stone count in each square with the built-up area in each square. Yellow highlights show architectural features. 


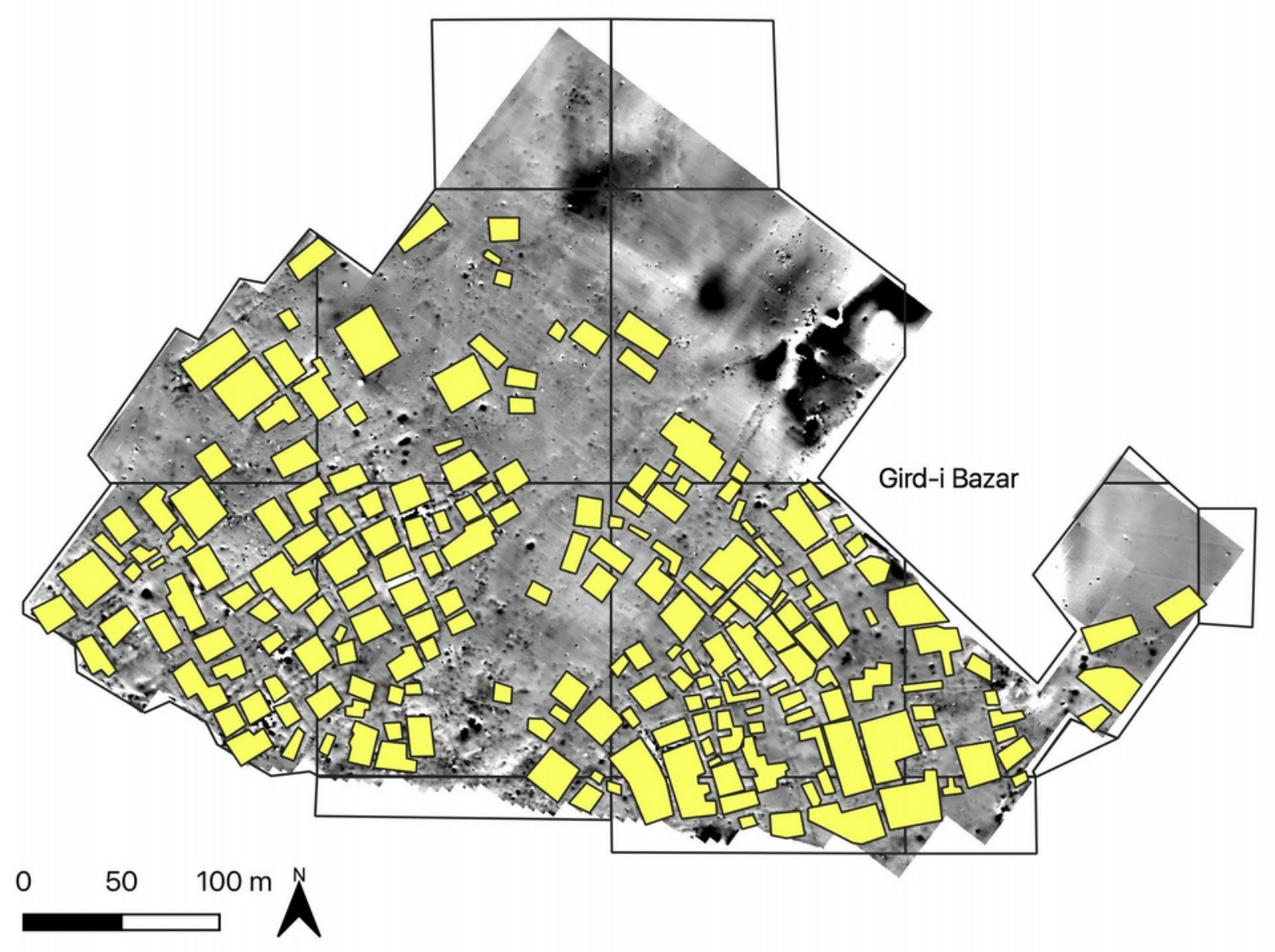

Figure 12. Result of the second regression analysis between the stone count and the built-up area based on the $150 \times 150$ m grid. 


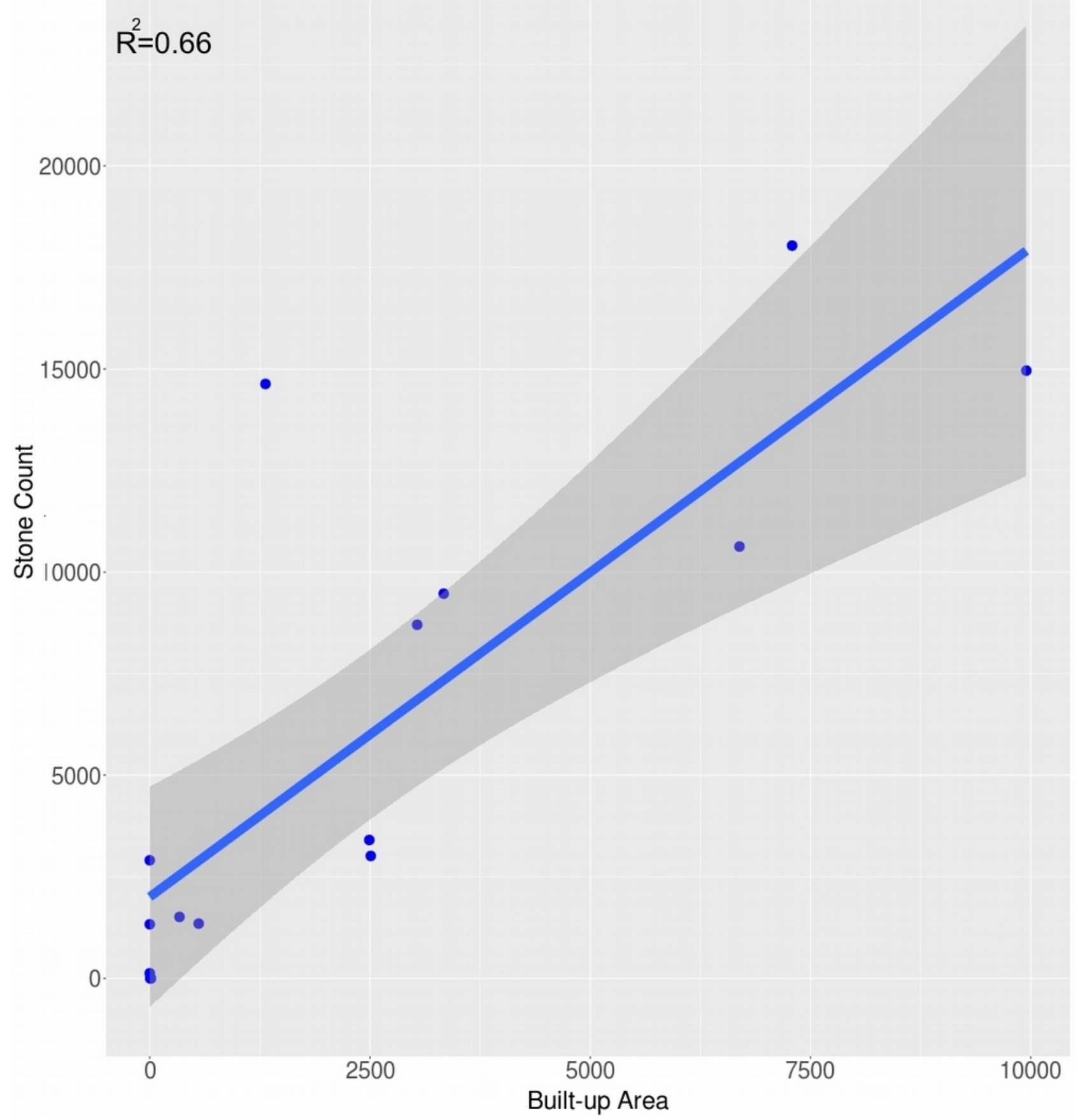

Figure 13. The 5 sub-areas in which the magnetogram has been divided in order to compare the stone count with the built-up area in each sub-area. Yellow highlights show the architectural features. 


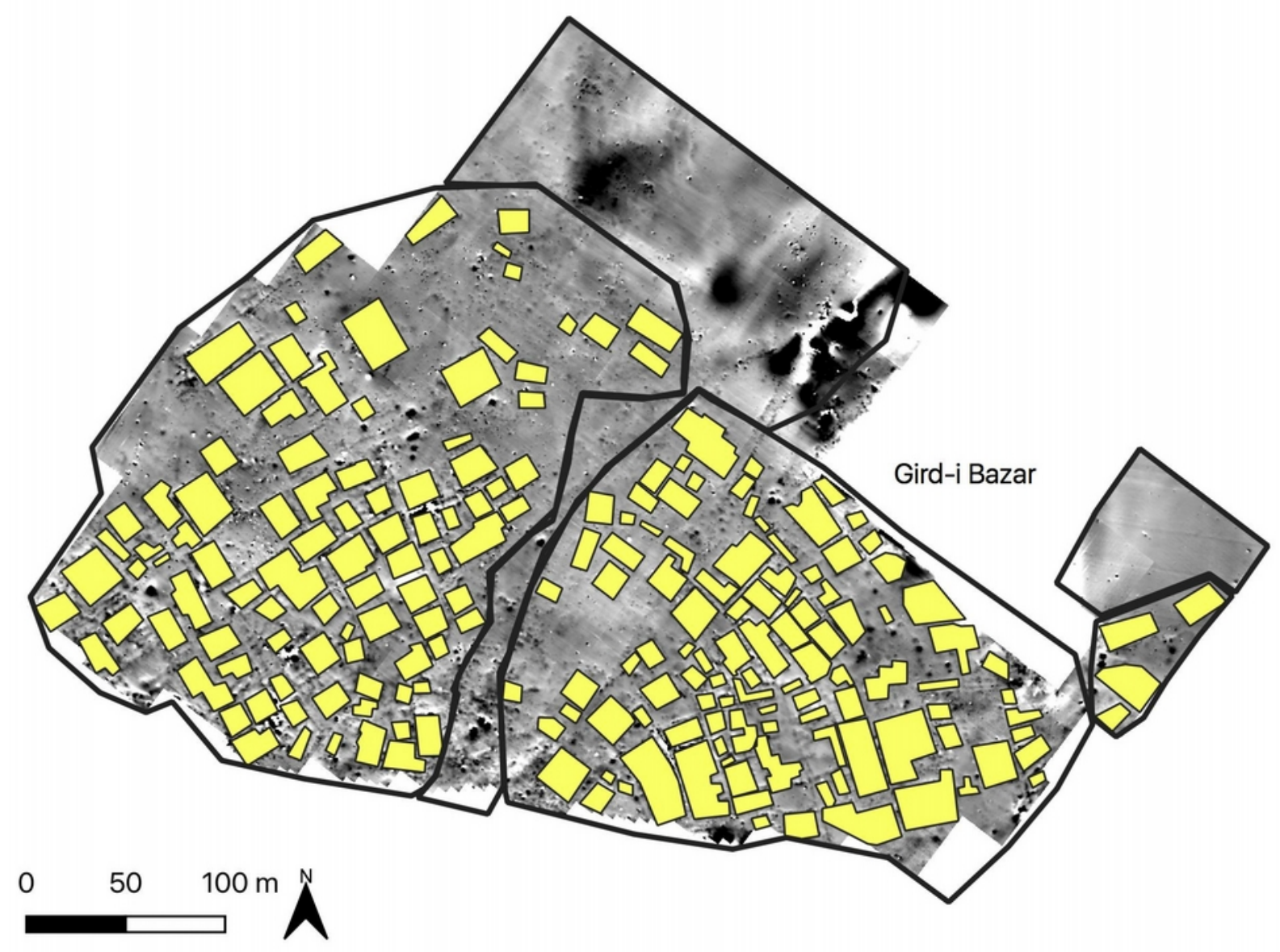

Figure 14. Result of the first regression analysis between the stone count and the built-up area based on the 5 sub-areas. 


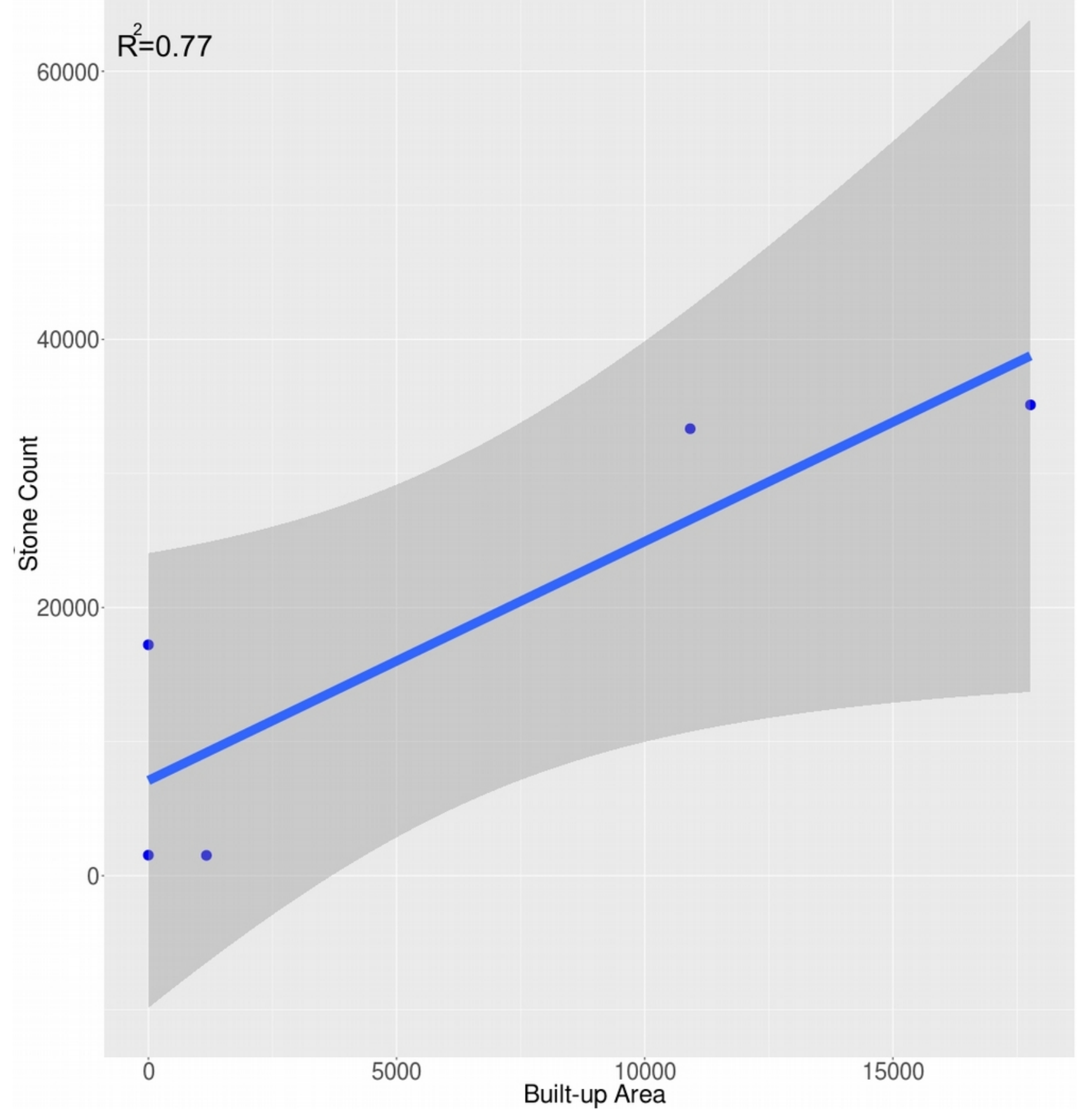

\section{Discussion}

Initially, we did not know the presence of an archaeological site in the area investigated, at least beyond a smaller area initially investigated (that is Gird-i Bazar, see Figure 2); the larger site was only discovered accidentally using what we had thought were off-site trenches that happened to then reveal intact architecture. Surface survey did not prove to be conclusive. Relatively flat sites and those that have relatively fewer surface ceramics, such as a portion of the space within the Dinka Settlement Complex, make detection of ancient settlements more difficult, and methods that do not require a high degree of dependence on mounding and surface ceramics might be needed for conducting broader site reconnaissance. Field methods that use UAV imagery need to be developed so that the full variety of sites can be more easily detected in regions such as the Middle East. Of course, ground truthing is required in the case of remotely sensed imagery, such as the presentation 
we give, but imagery can assist in at least demonstrating the likely presence of an ancient settlement that can then direct archaeologists to conduct focused research in areas where potential sites are identified. Our attempt at creating an approach towards relatively flat sites that incorporate stone architecture has yielded some primary observations. We can conclude that stone concentrations can be useful for finding archaeological sites. As seen above and in the point pattern analysis, the stones on the surface of the study area cluster more within and around the identified archaeological site, as a consequence of architectural features that are below the surface but visible through geophysics. This result indicates that surface stone concentrations can effectively identify not only relatively flat sites but also concentrations of stones are somewhat close to site boundaries, although they are far from exact in our case. This is expected, but it demonstrates that these methods are good for general site detection, rather than for mapping precise site boundaries (see also Bintliff 2000 on the definition of onsite and offsite boundaries). Using both the unsupervised classification and point pattern approaches effectively demonstrates the strong likelihood that a site existed.

Our results have also shown that stone concentrations are, in our case, matched to archaeological features, identified via geophysical prospection. The regression fit between stone counts and built-up area was stronger than sherd counts and built-up area. While the fit between stone counts and built-up area is relatively strong at a coarse scale (that is the 5 sub-areas), the result for a more fine-scaled analysis (that is the $150 \mathrm{x} 150 \mathrm{~m}$ grid) did not show as strong a positive fit, likely due to the movement of stones through anthropogenic activity (destruction of walls, plowing) and general taphonomic processes. Employing the detection of stones via UAV imagery to find a site proved generally successful for indicating an area that was more likely to have had ancient architecture, demonstrating its utility for site survey. On the other hand, the low density of surface ceramics may have been due to taphonomic processes within the region or simply because fewer ceramic objects were used on site. Increasing tools used to identify sites by developing new survey methods is critically necessary for areas with low concentrations of ceramic remains. With the advent of relatively cheap UAVs, aerial imagery has grown easier to obtain.

Applying a combination of methods for site detection might be the most useful technique in areas with low visibility and minimal surface cultural remains, particularly the combination of satellite and UAV imagery and geophysics which we have just demonstrated (Lin et al. 2011). Geophysical prospection is very time consuming. Based on imagery from UAVs, with their ability to detect features as small as cobblestones, the use of site detection techniques that deploy point pattern analysis, such as applying k-nearest neighbor, may be a relatively quick way to detect many sites across wide distances. Similar to all remote sensing techniques, ground truthing is only possible with some form of archaeological method, such as excavation or geophysical prospection. In this case, areas that show point concentrations that deviate from the wider background could be sufficient to indicate a site warranting further targeted investigation or prospection. The detection of possible sites could then be used to direct archaeologists where to look in places where the terrain is relatively flat and ceramics might be limited on the surface.

In addition to the point pattern analysis, the classification method deployed, which used UAV imagery from a relatively simple camera, proved effective in determining where stones concentrate, even when the equipment was not ideal for the task. The results from the precision test and PPV value show that the unsupervised classification applying k-means clustering was useful in making possible surface stone detection, certainly facilitating the counting of many stones, where only one class was needed to find the majority of stones. This result was likely due to the excellent conditions we had for aerial photography (with clear light and minimal cloud cover) as well as to the fact that vegetation was limited to only a few areas. The precision of our results may have decreased had these conditions not been present. Overall, in areas where stone architecture was present, surface stones may be a better proxy than surface ceramics or mounding for the detection of ancient settlements in regions similar to the flat area described in this study. Nevertheless, where there is dependence on relatively simple cameras on UAVs, both the quality of the light and surface conditions must be considered for the easiest detection of stone concentrations. 


\section{Conclusion}

We see from the results above that integrating regional geology and aerial imagery have demonstrated that the pattern of surface stones evident in the Dinka Settlement Complex relates to architectural remains. Surface stone anomalies are detectable because concentrations of stones vary from what otherwise might be normal background due to anthropogenic transportation of stones. The approaches presented here could be extended to wider regions of analysis using wider survey coverage from drone imagery or even satellite-based images if high resolutions are possible. The methods used could be extended to the wider region where a similar geology has been observed; surveys of the wider region of Iraqi Kurdistan would be possible, given that much of the country consists of similar mountainous areas interspersed with valleys. Automating analysis could also make the method quicker to deploy, such as in interlinking the clustering algorithm with regression and point pattern analyses. Background geological studies are also critical for determining whether any surfaces stones found within a given area represent an expected natural feature or not, as we have demonstrated. Integrating geoarchaeological trenches made it evident that the surface stones had been anthropogenically deposited, suggesting that this remains a crucial step in the process when applying the methods presented here to different regions.

The camera that we used was a simple camera without additional multispectral coverage or thermal imaging. This placed limitations on our remote sensing capabilities. More sophisticated cameras could use surface reflect and heat qualities inherent in stone to detect stone concentrations. This would result in an even greater level of precision in stone detection, including the ability to "see" through vegetation, ensuring that variations in stone concentrations across different terrains are better recognized. In mountainous and other regions where stones were commonly used for building, we have suggested stone architectural elements might be a better source of information than other archaeological methods that depend on different proxies, such as identification of mounds or surface ceramic surveys. Deploying UAVs across a wider area and detecting anomalies that indicate deviation from normal stone-concentration patterns could, therefore, indicate the presence of archaeological sites across a wider region, similar to what we described have here for Iraqi Kurdistan. The method, therefore, facilitates the detection of potential archaeological sites that have otherwise been difficult to locate previously.

\section{Acknowledgements}

This paper originated from research undertaken within the Alexander von Humboldt Foundation and the Peshdar Plain Project directed by Karen Radner (LMU Munich, Alexander von Humboldt Professorship of the Ancient History of the Near and Middle East). A first draft was written while Mark Altaweel held a fellowship at the Center for Advanced Studies (CAS) at LMU Munich as part of the Research Focus group "Settlements between Diversity and Homogeneity" led by Radner. We thank both the Alexander von Humboldt Professorship and the CAS for providing generous support and assistance for this research. We thank the Sulaymaniyah Directorate of Antiquities and Heritage for permission and assistance in making this work possible.

\section{References}

Adams, R. McC. 1981. Heartland of Cities: Surveys of Ancient Settlement and Land Use on the Central Floodplain of the Euphrates. Chicago: University of Chicago Press.

Altaweel, M. 2005. “The Use of ASTER Satellite Imagery in Archaeological Contexts.” Archaeological Prospection 12 (3): 151-66._https://doi.org/10.1002/arp.254.

Altaweel, M., A. Marsh, S. Mühl, O. Nieuwenhuyse, K. Radner, K. Rasheed, and S. A. Saber. 2012. "New Investigations in the Environment, History, and Archaeology of the Iraqi Hilly Flanks: 
Shahrizor Survey Project 2009-2011.” Iraq 74: 1-35.

Altaweel, M., and A. Marsh. 2016. "Landscape and geoarchaeology of the Bora Plain.” In Exploring the Neo-Assyrian Frontier with Western Iran: The 2015 Season at Gird-i Bazar and Qalat-I Dinka, edited by K. Radner, K, F. J. Kreppner, and A. Squitieri, 23-28. Gladbeck: PeWe Verlag.

Banning, E. B. 1996. "Highlands and Lowlands: Problems and Survey Frameworks for Rural Archaeology in the Near East.” Bulletin of the American Schools for Oriental Research 301: 25-45.

Braidwood, R. 1937. Mounds in the Plain of Antioch: an Archaeological Survey. Chicago: University of Chicago Press.

Beck, A., G. Philip, M. Abdulkarim, and D. Donoghue. 2007. "Evaluation of Corona and Ikonos High Resolution Satellite Imagery for Archaeological Prospection in Western Syria.” Antiquity 81 (311): 161-75._https://doi.org/10.1017/S0003598X00094916.

Bintliff, J., 2000. “The Concepts of 'Site' and 'Offsite' Archaeology in Surface Artefact Survey.” In: M Non-Destructive Techniques Applied to Landscape Archaeology (The Archaeology of the Mediterranean Landscape, Populus Monograph, 4, Band 4), edited by M. Pasquinucci, and F. Trement, 200-215. Oxford: Oxbow Books.

Brenning, A. 2009. "Benchmarking Classifiers to Optimally Integrate Terrain Analysis and Multispectral Remote Sensing in Automatic Rock Glacier Detection.” Remote Sensing of Environment 113 (1): 239-47. https://doi.org/10.1016/j.rse.2008.09.005.

Casana, J. 2014. "New Approaches to Spatial Archaeometry: Applications from the Near East." Near Eastern Archaeology 77 (3): 171-75. https://doi.org/10.5615/neareastarch.77.3.0171.

Downey, K. 2018. “The Sasanian Cemetery of Gird-i Bazar.” In The Dinka Settlement Complex 2017. The Final Season at Gird-i Bazar and First Work in the Lower Town, edited by K. Radner, F. J. Kreppner, and A. Squitieri, 173-184. Gladbeck: PeWe-Verlag

Fassbinder , J., A. Ašandulesei 2016. “The Magnetometer Survey of Qalat-i Dinka and Gird-i Bazar 2015.” In Unearthing the Dinka Settlement Complex. The 2016 Season at Gird-i Bazar and Qalat-i Dinka, edited by K. Radner, F. J. Kreppner, and A. Squitieri, 36-42. Gladbeck: PeWe-Verlag.

Fassbinder, J., A. Ašandulesei, M. Scheiblecker 2017. "Magnetometer Prospection at the Dinka Settlement Complex and Gawr Miran, 2016.” In Unearthing the Dinka Settlement Complex. The 2016 Season at Gird-i Bazar and Qalat-i Dinka, edited by K. Radner, F. J. Kreppner, and A. Squitieri, 18-28. Gladbeck: PeWe-Verlag.

Fassbinder, J., A. Ašandulesei, M. Scheiblecker 2018. “The 2017 Magnetometer Survey of the Dinka Settlement Complex.” In The Dinka Settlement Complex 2017. The Final Season at Gird-i Bazar and First Work in the Lower Town, edited by K. Radner, F. J. Kreppner, and A. Squitieri, 2023. Gladbeck: PeWe-Verlag.

Finkbeiner, U. 1991. Uruk. Kampagne 35-37, 1982-1984. Die archäologische Oberflächenuntersuchung (Survey). Endberichte 4. Minz: von Zaibern.

Finlayson, B., S. J. Mithen, M. Najjar, S. Smith, D. Maricevic, N. Pankhurst, and L. Yeomans. 2011. "Architecture, Sedentism, and Social Complexity at Pre-Pottery Neolithic A WF16, Southern 
Jordan.” Proceedings of the National Academy of Sciences 108 (20): 8183-88.

Gibson, McG. 1972. The City and Area of Kish. Miami, FL: Field Research Projects.

Giraud, J. 2016. “Surface Survey of the Dinka Settlement Complex, 2013-2015.” In Exploring the Neo-Assyrian Frontier with Western Iran: The 2015 Season at Gird-i Bazar and Qalat-i Dinka, edited by K. Radner, F. J. Kreppner, and A. Squitieri, 29-35. Gladbeck: PeWe-Verlag.

Hiebert, F. T. 1994. Origins of the Bronze Age Oasis Civilization in Central Asia. American School of Prehistoric Research 42. Cambridge, MA: Peabody Museum of Archaeology and Ethnology, Harvard University.

Hofmann, R. 2012. “Tells: Reflections of Social and Environmental Spaces- an Introduction.” In Tells: Social and Environmental Space. Proceedings of the International Workshop SocioEnvironmental Dynamics over the Last 12.000 Years: The Creation of Landscapes II (14th - 18th March 2011), edited by R. Hofmann, 15-18. Universitätsforschungen Zur Prähistorischen Archäologie Vol. 3. Bonn: Habelt.

Hritz, C. 2014. "Contributions of GIS and Satellite-based Remote Sensing to Landscape Archaeology“ in the Middle East.” Journal of Archaeological Research 22: 229-276.

Kemp, B. J. 1977. “The Early Development of Towns in Egypt.” Antiquity 51 (203): 185-200. https://doi.org/10.1017/S0003598X00071702.

Kennedy, D., and R. Bewley. 2009. “Aerial Archaeology in Jordan.” Antiquity 83 (319): 69-81. https://doi.org/10.1017/S0003598X00098094.

Kennedy, D. 1998. "Declassified Satellite Photographs and Archaeology in the Middle East: Case Studies from Turkey.” Antiquity 72 (277): 553-61.https://doi.org/10.1017/S0003598X0008697X.

Kouchoukos, N. 2001. "Satellite Images and Near Eastern Landscapes.” Near Eastern Archaeology 64 (1-2): 80-91._https://doi.org/10.2307/3210823.

Lloyd, S. 1963. Mounds of the Near East. Edinburgh: Edinburgh University.

Lasaponara, R., and N. Masini. 2007. "Detection of Archaeological Crop Marks by Using Satellite QuickBird Multispectral Imagery.” Journal of Archaeological Science 34 (2): 214-21. https://doi.org/10.1016/j.jas.2006.04.014.

Lin, A. Y-M., A. Novo, S. Har-Noy, N. D. Ricklin, and K. Stamatiou. 2011. “Combining GeoEye-1 Satellite Remote Sensing, UAV Aerial Imaging, and Geophysical Surveys in Anomaly Detection Applied to Archaeology.” IEEE Journal of Selected Topics in Applied Earth Observations and Remote Sensing 4 (4): 870-76. https://doi.org/10.1109/JSTARS.2011.2143696.

Menze, B. H., and J. A. Ur. 2012. "Mapping Patterns of Long-Term Settlement in Northern Mesopotamia at a Large Scale.” Proceedings of the National Academy of Sciences 109 (14): E77887. https://doi.org/10.1073/pnas.1115472109.

Parcak, S. 2007. "Satellite Remote Sensing Methods for Monitoring Archaeological Tells in the Middle East.” Journal of Field Archaeology 32 (1): 65-81._ https://doi.org/10.1179/009346907791071773. 
Parcak, S., and C. A. Tuttle. 2016. "Hiding in Plain Sight: The Discovery of a New Monumental Structure at Petra, Jordan, Using WorldView-1 and WorldView-2 Satellite Imagery.” Bulletin of the American Schools of Oriental Research 375 (May): 35-51. https://doi.org/10.5615/bullamerschoorie.375.0035.

Philip, G., F. Jabour, A. Beck, M. Bshesh, J. Grove, A. Kirk, and A. Millard. 2002. "Settlement and Landscape Development in the Homs Region, Syria: Research Questions, Preliminary Results 1999-2000 and Future Potential.” Levant 34 (1): 1-23. https://doi.org/10.1179/lev.2002.34.1.1.

Radner, K., F. J. Kreppner, A. Squitieri (eds). 2016. Exploring the Neo-Assyrian Frontier with Western Iran: The 2015 Season at Gird-i Bazar and Qalat-i Dinka. Peshdar Plain Project Publications, Vol. 1. Gladbeck: PeWe-Verlag.

Radner, K., F. J. Kreppner, and A. Squitieri (eds). 2017. Unearthing the Dinka Settlement Complex. The 2016 Season at Gird-i Bazar and Qalat-i Dinka. Peshdar Plain Project Publications, Vol. 2. Gladbeck: PeWe-Verlag.

Radner, K., F. J. Kreppner, and A. Squitieri (eds). 2018. The Dinka Settlement Complex 2017. The Final Season at Gird-i Bazar and First Work in the Lower Town. Peshdar Plain Project Publications, Vol. 3. Gladbeck: PeWe-Verlag.

Richards, J. A. 2013a. Remote Sensing Digital Image Analysis: An Introduction. Fifth edition. Berlin: Springer.

Richards, J. A. 2013b. “Supervised Classification Techniques.” In Remote Sensing Digital Image Analysis, edited by John A. Richards, 247-318. Berlin, Heidelberg: Springer Berlin Heidelberg. https://doi.org/10.1007/978-3-642-30062-2_8.

Rosen, A. M. 1986. Cities of Clay: The Geoarchaeology of Tells. Chicago: University of Chicago Press.

Sissakian, V. K, and S. F. Fouad 2015. “Geological Map of Sulaymaniyah Quadrangle”. Journal of Zankoi Sulaimani 0 Part A: 1-11.https://doi.org/10.13140/RG.2.1.5109.0642.

Sissakian, V. K, A. D. A. Ahad, N. Al-Ansari, R. Hassan, and S. Knuttson 2016. “The Regional Geology of Dokan Area, NE Iraq.” Journal of Earth Sciences and Geotechnical Engineering, 6 (3): 35-63.

Squitieri, A. 2018. "Preliminary report on the 2018 Dinka Lower Town Campaign (DLT3)”, Ancient History Department, LMU Munich, 2018. Online report: http://www.en.ag.geschichte.unimuenchen.de/research/peshdar-plain-project/peshdar-plain-project2018dlt/.

Ur, J., L. De Jong, J. Giraud, J. F. Osborne, and J. MacGinnis. 2013. “Ancient Cities and Landscapes in the Kurdistan Region of Iraq: The Erbil Plain Archaeological Survey 2012 Season”. Iraq 75: 89-117._https://doi.org/10.1017/S0021088900000425

Wilkinson, K. N., A. R. Beck, and G. Philip. 2006. "Satellite Imagery as a Resource in the Prospection for Archaeological Sites in Central Syria.” Geoarchaeology 21 (7): 735-50. https://doi.org/10.1002/gea.20136.

Wilkinson, T. J. 1982. "The Definition of Ancient Manured Zones by Extensive Sherd-Sampling Techniques.” Journal of Field Archaeology 9: 323- 333. 
Wilkinson, T. J. 2000. "Regional Approaches to Mesopotamian Archaeology: The Contribution of Archaeological Surveys.” Journal of Archaeological Research 8 (3): 219-67.

https://doi.org/10.1023/A:1009487620969.

Wilkinson, T. J. 2003. Archaeological Landscapes of the Near East. Tucson: University of Arizona Press.

Wilkinson, T. J, N. Galiatsatos, D. Lawrence, A. Ricci, R. Dunford, and G. Philip. 2012. "Late Chalcolithic and Early Bronze Age Landscapes of Settlement and Mobility in the Middle Euphrates: A Reassessment.” Levant 44 (2): 139-85._https://doi.org/10.1179/0075891412Z.0000000007. 